\title{
Long-term ozone exposures and cause-specific mortality in a US Medicare cohort
}

\author{
Fatemeh Kazemiparkouhi ${ }^{1} \cdot$ Ki-Do Eum ${ }^{1} \cdot$ Bingyu Wang $^{2} \cdot$ Justin Manjourides $^{3} \cdot$ Helen H. Suh ${ }^{1}$
}

Received: 7 November 2018 / Revised: 20 February 2019 / Accepted: 8 March 2019 / Published online: 16 April 2019

(c) The Author(s) 2019. This article is published with open access

\begin{abstract}
We examined the association of long-term, daily 1-h maximum $\mathrm{O}_{3}$ (ozone) exposures on cause-specific mortality for 22.2 million US Medicare beneficiaries between 2000-2008. We modeled the association between $\mathrm{O}_{3}$ and mortality using agegender-race stratified log-linear regression models, adjusted for state of residence. We examined confounding by (1) adjusting for $\mathrm{PM}_{2.5}$ (particles with aerodynamic diameters $<2.5 \mu \mathrm{m}$ ) and $\mathrm{NO}_{2}$ (nitrogen dioxide) exposures, temperature, and neighborhood-level characteristics and behaviors, and (2) decomposing $\mathrm{O}_{3}$ into its temporal and spatio-temporal components and comparing estimated risk ratios. We also examined sensitivity of our results to alternate exposure measures based on warm-season 8-h daily maximum and 24-h average exposures. We found increased risks from long-term $\mathrm{O}_{3}$ exposures to be strongest and most consistent for mortality from respiratory disease $(1.030,95 \% \mathrm{CI}: 1.027,1.034)$ (including COPD (chronic obstructive pulmonary disease)), CHF (congestive heart failure), and lung cancer (1.015, 95\% CI: 1.010, 1.020), with no evidence of confounding by $\mathrm{PM}_{2.5}, \mathrm{NO}_{2}$, and temperature and with results similar across $\mathrm{O}_{3}$ exposure measures. While significant, associations between long-term $\mathrm{O}_{3}$ exposures and CVD (cardiovascular)-related mortality $(1.005,95 \%$ CI: $1.003,1.007)$ were confounded by $\mathrm{PM}_{2.5}$ and varied with the exposure measure, with associations no longer significantly positive when warm-season 8-h maximum or 24-h average $\mathrm{O}_{3}$ was used to assess exposures. In this large study, we provide strong evidence that $\mathrm{O}_{3}$ exposure is associated with mortality from respiratory-related causes and for the first-time, lung cancer, but raise questions regarding $\mathrm{O}_{3}$-related impacts on CVD mortality. Our findings demonstrate the need to further identify potential confounders.
\end{abstract}

Keywords $\mathrm{O}_{3} \cdot$ Air pollution $\cdot$ Long-term exposure $\cdot$ Cause-specific mortality $\cdot$ Confounding

\section{Introduction}

A small but growing number of studies have examined associations between long-term exposure to $\mathrm{O}_{3}$ and causespecific mortality [1-4], with mixed results. In an analysis

Supplementary information The online version of this article (https:// doi.org/10.1038/s41370-019-0135-4) contains supplementary material, which is available to authorized users.

Fatemeh Kazemiparkouhi

fkazem01@tufts.edu

1 Department of Civil and Environmental Engineering, Tufts University, Medford, MA, USA

2 College of Computer and Information Science, Northeastern University, Boston, MA, USA

3 Department of Health Sciences, Northeastern University, Boston, MA, USA of the ACS (American Cancer Society) cohort, for example, Jerrett et al. [1] found significant associations between warm-season averages of 1-h daily maximum $\mathrm{O}_{3}$ exposures and increased CVD, IHD (ischemic heart disease), respiratory and cardiopulmonary mortality, but not all-cause mortality. However, with the exception of respiratory mortality, these associations disappeared after adjustment for $\mathrm{PM}_{2.5}$, suggesting confounding by $\mathrm{PM}_{2.5}$ of $\mathrm{O}_{3}$-mortality associations for cardiovascular-related causes [1].

Correspondingly, in a follow-up study of the ACS [2], associations of year round and warm-season averages of 8-h daily maximum $\mathrm{O}_{3}$ were significantly and positively associated with all-cause, circulatory, cardiovascular, and respiratory mortality. Unlike the earlier study, however, these associations, including that for CVD mortality, were not confounded by $\mathrm{PM}_{2.5}$. Findings from the CanCHEC study (Canadian Census Health and Environment Cohort) [3], on the other hand, showed significant and positive associations between warm-season 8 -h daily maximum $\mathrm{O}_{3}$ 
and non-accidental, cardiometabolic disease, and cardiovascular mortality, but not respiratory, CBV (cerebrovascular disease), and lung cancer. Significant associations remained significant but were attenuated after adjustment for $\mathrm{PM}_{2.5}$ and $\mathrm{NO}_{2}$. In contrast, warm-season averages of 24-h averaged $\mathrm{O}_{3}$ exposure were not associated with all-cause, cardiovascular, $\mathrm{CBV}$, non-malignant respiratory, and lung cancer mortality in the California Teacher's Study [4]. While these studies suggest a relationship between average peak $\mathrm{O}_{3}$ exposures and mortality, their associations for specific causes of mortality are inconsistent, perhaps due to their use of different measures of long-term $\mathrm{O}_{3}$ exposure, which may not only affect $\mathrm{O}_{3}$ 's impacts on health but also confounding of $\mathrm{O}_{3}$-mortality associations by $\mathrm{PM}_{2.5}$ and other pollutants.

Yet, few studies have examined how different $\mathrm{O}_{3}$ exposure measures impact associations with specific causes of death and how these impacts may affect control for potential confounders, such as $\mathrm{PM}_{2.5}$ and other air pollutants. Our ability to understand these impacts may be furthered by methods that assess unmeasured confounding in air-pollution-health effect models, such as that developed by Greven et al. [5]. We used this method to characterize unmeasured confounding in our recent studies of $\mathrm{PM}_{2.5}$ [6] and $\mathrm{NO}_{2}$-associated [7] mortality risks. We showed significant and positive associations between both $\mathrm{PM}_{2.5}$ and $\mathrm{NO}_{2}$ associations and several causes of death, even after adjustment for other air pollutants and neighborhood-level SES (socio-economic status) and behavioral factors; however, unmeasured confounding of these risks remained. No such method has yet been applied to $\mathrm{O}_{3}$ and cause-specific mortality.

To address this issue, we examined the association between long-term $\mathrm{O}_{3}$ exposures and all-cause and cause-specific mortality in a cohort of $>22$ million Medicare beneficiaries living across the conterminous US (United States) and assessed the consistency of these associations across different measures of exposure, control for confounders, and as modified by region of residence and urbanicity.

\section{Materials and methods}

This study was approved by the Institutional Review Board of Tufts and Northeastern Universities.

\section{Air pollution data}

We obtained hourly $\mathrm{O}_{3}$ concentrations from 1151 air quality monitors from the US EPA (Environmental Protection Agency) AQS (Air Quality System) for 2000 through 2008. These monitors, $80 \%$ of which were located in urban areas, were selected based on their having hourly measurements for $4+$ calendar years, with each year having data for at least five warm-season months (April-September), with each month having at least $75 \%$ valid daily measurements. Daily measurements were determined to be valid if $75 \%$ of its hourly measurements were available. For each monitor and day, we calculated the daily maximum hourly $\mathrm{O}_{3}$ concentration as our main exposure measure and averaged daily values from April through September to obtain warmseason average, 1-h daily maximum $\mathrm{O}_{3}$ concentrations (hereafter referred to as the warm-season 1-h maximum $\mathrm{O}_{3}$ ) for each monitor and calendar year, as used in Jerrett et al. [1]. In addition, we calculated two secondary exposure measures, including the (1) warm-season average of daily 8$\mathrm{h}$ maximum and (2) warm-season average of 24-h average.

To examine potential confounding, we also estimated (1) 1-year moving average $\mathrm{PM}_{2.5}$ concentrations using well validated GIS-based (Geographical Information System) spatio-temporal models that estimated daily $\mathrm{PM}_{2.5}$ exposures on a $6 \mathrm{~km}$ grid covering the conterminous US [8], (2) 1-year moving average $\mathrm{NO}_{2}$ concentrations using land use regression models developed by Bechle et al. [9] that estimated monthly $\mathrm{NO}_{2}$ exposure for census blocks, and (3) 3day moving average temperature using spatio-temporal GAMs that estimated daily temperature on a $6 \mathrm{~km}$ grid [8]. $\mathrm{PM}_{2.5}, \mathrm{NO}_{2}$, and temperature values were linked to corresponding $\mathrm{O}_{3}$ exposures using the grid point or in the case of $\mathrm{NO}_{2}$, the census block closest to each of our study's $\mathrm{O}_{3}$ monitors.

\section{Medicare beneficiaries}

We compiled enrollment data from the Centers for Medicare and Medicaid Services for 52.9 million Medicare beneficiaries aged 65 to 120 between 2000-2008. We identified those beneficiaries that resided in ZIP (Zone Improvement Plan) codes with a geographic centroid within a $10 \mathrm{~km}$ of an eligible $\mathrm{O}_{3}$ monitor between 2000-2008. For each enrollee, we obtained information on date of birth, gender, race/ethnicity, ZIP code of residence, and survival. Using the ICD-9 (International Classification of Disease 9th version) codes from the National Death Index, we extracted mortality from non-accidental and accidental causes, as well as from all CVD (cardiovascular) and all respiratory-related causes, and specific subcategories, including IHD (ischemic heart disease), CBV (cerebrovascular) disease, CHF, COPD and pneumonia. Altogether, CVD and respiratory-related causes accounted for over $50 \%$ of all-cause mortality (Table 1). We computed the number of Medicare beneficiaries and cause-specific deaths for each 5-year age interval-gender-race (white/non-white) group, monitor, and study month. To avoid excessive zero counts, we collapsed ages 90 and above into one interval. 
Table 1 Summary statistics of ozone monitors and concentrations, Medicare enrollees, and cause-specific deaths among Medicare enrollees

\begin{tabular}{|c|c|c|c|c|}
\hline Characteristics & ICD -9 code & 25th Median 75 th ${ }^{a}$ & Total number & Total $\%$ \\
\hline Monitoring stations & & & 1151 & \\
\hline $\mathrm{O}_{3}{ }^{\mathrm{b}}(\mathrm{ppb})$ & & 505560 & & \\
\hline Medicare enrollees & & $385811,69728,311$ & $22,159,190$ & \\
\hline All-cause deaths & & 7242,4716458 & $5,766,091$ & \\
\hline Non-accidental & $\mathrm{A}-\mathrm{R}$ & 7042,4126293 & $5,637,693$ & 97.8 \\
\hline Accidental & $\mathrm{V}-\mathrm{Y}$ & ${ }_{21} 62 \quad 155$ & 128,372 & 2.2 \\
\hline All cardiovascular & I00-I99 & 2799562537 & $2,333,681$ & 40.5 \\
\hline IHD & $\mathrm{I} 20-\mathrm{I} 25$ & 1364611226 & $1,245,401$ & 21.6 \\
\hline $\mathrm{CBV}$ & I60-I69 & 55183477 & 410,187 & 7.1 \\
\hline $\mathrm{CHF}$ & $\mathrm{I} 50$ & $2173 \quad 183$ & 158,649 & 2.8 \\
\hline All respiratory & J00-J99 & 85281725 & 633,216 & 11.0 \\
\hline COPD & $\mathrm{J} 40-\mathrm{J} 44$ & 73155380 & 328,957 & 5.7 \\
\hline Pneumonia & $\mathrm{J} 12-\mathrm{J} 18$ & $2067 \quad 177$ & 174,932 & 3.0 \\
\hline All cancer & $\mathrm{C}-\mathrm{D}$ & 1565341437 & $1,277,716$ & 22.2 \\
\hline Lung cancer & $\mathrm{C} 34$ & 46155403 & 350,357 & 6.1 \\
\hline
\end{tabular}

Time period: 2000-2008, USA

$I C D-9$ the 9th revision of the International Classification of Disease, $O_{3}$ ozone, $I H D$ ischemic heart disease, $C B V$ cerebrovascular disease, $C H F$ congestive heart failure, $C O P D$ chronic obstructive pulmonary disease Medicare enrollees ages $65-120$

${ }^{a}$ Values are medians among locations and months, with 25th and 75th percentile given in subscripts

${ }^{\mathrm{b}}$ Warm-season average of daily 1-h maximum ozone concentrations

\section{Statistical analyses}

We linked demographic and mortality data for our Medicare beneficiary cohort to $\mathrm{O}_{3}$ concentrations measured at the monitor closest to the centroid of the ZIP code of residence.

As our main analysis, we used log-linear regression models to examine the association between warm-season averages of 1-h maximum $\mathrm{O}_{3}$ exposure and cause-specific mortality, stratified on age, gender, and race (White/nonWhite) and adjusted for state of residence in both single and two-pollutant models controlling for 1-year moving average $\mathrm{PM}_{2.5}$ (Supplementary Appendix 1, SI (Supplementary Information)). All results are expressed as the RR (risk ratio) of dying in a given month per $10 \mathrm{ppb}$ (part per billion) increase in $\mathrm{O}_{3}$ exposure and associated 95\% CI (confidence interval).

We evaluated the sensitivity of our findings to the exposure measure, replacing warm-season 1-h maximum $\mathrm{O}_{3}$ concentrations with (1) warm-season average of daily 8-h maximum or (2) warm-season average of 24-h average $\mathrm{O}_{3}$ concentrations in our health models in single and twopollutant models controlling for $\mathrm{PM}_{2.5}$. We also examined whether associations differed by region of residence (Northeast, Midwest, South, West) as classified using US Census Bureau classifications (Fig. S1, SI), and by urbanicity (urban vs. non-urban) using USGS (United States Geological Survey) Land Cover Trends classifications by stratifying our data into corresponding groups.
To further assess potential confounding of an association between $\mathrm{O}_{3}$ and mortality, we fit models that additionally adjusted for $\mathrm{NO}_{2}$ and 3-day moving average temperature. We also fit multi-variable models for beneficiaries living near the 836 of the 1151 monitors for which we had demographic covariates from the 2000 U.S. Census [10]. We assessed the association of $\mathrm{O}_{3}$ and mortality adjusting for $\mathrm{PM}_{2.5}$ with and without controlling for the proportion of the population $\geq 25$ years old with at least a high school degree, median income, and proportion of the population living in urban area within the census tract corresponding to the ZIP code centroid. The spatial distribution of the monitors with Census data was similar to that for all monitors, although with fewer monitors in the Midwest (18\% vs. $24 \%$ overall) and more monitors in the West (31\% vs. $26 \%$ overall) (Table S1, SI).

We also examined potential confounding by behavioral covariates measured in Selected Metropolitan/Micropolitan Area Risk Trends of the BRFSS (Behavioral Risk Factor Surveillance System) [11] for the subset of beneficiaries living near monitors (586 of 1151 monitors) located in a county with BRFSS data. For these beneficiaries, we assessed the association of $\mathrm{O}_{3}$ and mortality, adjusting for $\mathrm{PM}_{2.5}$, and with and without adjusting for potential confounding by monthly county-level prevalence of current smokers, diabetics, heavy drinkers (i.e., >two drinks per day), asthma, average median income, and body mass index. Note that the spatial distribution of the monitors with 
BRFSS data was similar to that for all monitors, although with fewer monitors in the Midwest (16\% vs. $24 \%$ overall) and more monitors in the West (31\% vs. $26 \%$ overall) (Table S1, SI). The spatial distribution of the monitors with Census and BRFSS data was similar by region.

To examine the extent to which our findings remain affected by confounding, we followed the method suggested by Greven et al. [5] and decomposed $\mathrm{O}_{3}$ into two orthogonal, component measures, "temporal" and "spatiotemporal" $\mathrm{O}_{3}$, and estimated their associations with causespecific mortality in base, $\mathrm{PM}_{2.5}$-adjusted, and BRFSSadjusted models (Supplementary Appendix 1, SI). "Temporal" $\mathrm{O}_{3}$, which represents the national temporal trends in monthly $\mathrm{O}_{3}$ concentrations, is $\mathrm{O}_{3}$ centered by the average concentrations for all monitors and across the study period; "spatio-temporal" $\mathrm{O}_{3}$ is a measure of the monitor-specific temporal trends in monthly $\mathrm{O}_{3}$ concentrations compared to the national "temporal" trends. In the absence of residual confounding by long-term time trends of mortality, estimates of the "temporal" and "spatio-temporal" $\mathrm{O}_{3}$ should be similar.

\section{Results}

Our study population included 22.2 million Medicare enrollees residing in 260 metropolitan areas across the US (Table 1), comprising $42 \%$ of all Medicare enrollees. During the study period, 5.8 million deaths were reported; $97.8 \%$ from non-accidental causes. CVD accounted for $40.5 \%$ of all mortality, followed by cancer $(22.2 \%)$ and respiratory mortality (11\%). More than $50 \%$ of all CVD mortality was caused by IHD. Fifty-two percent of respiratory deaths were attributed to COPD and $27.6 \%$ to pneumonia, while $27.4 \%$ of cancer deaths were attributed to lung cancer. The warm-season average of 1-h maximum $\mathrm{O}_{3}$ concentration across all monitors and years was $56 \mathrm{ppb}$ (9 ppb) and exhibited no consistent temporal trend over the study period (Fig. S2, SI). Warm average concentrations varied by region, with concentrations highest in the West (Fig. S2, SI). Warm-season averages of 1-h maximum $\mathrm{O}_{3}$ were strongly correlated with corresponding averages of 8 -h maximum $(r=0.98)$ and 24-h average $(r=0.74)$ levels. The correlation coefficient between the warm-season average of 1-h maximum $\mathrm{O}_{3}$ and 1-year average $\mathrm{PM}_{2.5}$, 1-year average $\mathrm{NO}_{2}$, and 3-day average temperature equaled 0.24 , 0.26 , and 0.04 , respectively.

In single pollutant models we found a $10 \mathrm{ppb}$ increase in warm-season 1-h maximum $\mathrm{O}_{3}$ to be significantly associated with an increased risk of dying from all $(1.013 ; 95 \%$ CI: $1.012,1.014)$ and non-accidental causes $(1.014 ; 95 \%$ CI: $1.013,1.015)$, but not from accidental causes (0.998; 95\% CI: 0.991, 1.006) (Table 2). RRs were the highest for
Table 2 Mortality RRs $(95 \% \mathrm{CI})$ associated with a $10 \mathrm{ppb}$ increase in $\mathrm{O}_{3}$ : single pollutant and $\mathrm{PM}_{2.5}$-adjusted models

\begin{tabular}{lll}
\hline Cause of death & Single pollutant model & PM $_{2.5}$-adjusted model $^{\mathrm{b}}$ \\
\hline All-cause & $1.013(1.012-1.014)$ & $1.004(1.003-1.006)$ \\
$\quad$ Accidental & $0.998(0.991-1.006)$ & $1.010(1.002-1.017)$ \\
All cardiovascular & $1.027(1.025-1.028)$ & $1.005(1.003-1.007)$ \\
$\quad$ IHD & $1.043(1.041-1.045)$ & $1.008(1.006-1.011)$ \\
CBV & $1.012(1.008-1.016)$ & $0.993(0.989-0.997)$ \\
CHF & $1.052(1.045-1.060)$ & $1.063(1.055-1.071)$ \\
All respiratory & $1.036(1.032-1.039)$ & $1.030(1.027-1.034)$ \\
$\quad$ COPD & $1.065(1.060-1.069)$ & $1.072(1.067-1.077)$ \\
$\quad$ Pneumonia & $1.024(1.018-1.030)$ & $0.990(0.984-0.996)$ \\
All cancer & $1.000(0.998-1.003)$ & $0.995(0.993-0.998)$ \\
$\quad$ Lung cancer & $1.016(1.011-1.020)$ & $1.015(1.010-1.020)$ \\
\hline
\end{tabular}

Time period: 2000-2008, USA

$R R$ risk ratio, $C I$ confidence interval, $P M_{2.5}$ particles with aerodynamic diameters $<2.5 \mu \mathrm{m}, I H D$ ischemic heart disease, $C B V$ cerebrovascular disease, $C H F$ congestive heart failure, $C O P D$ chronic obstructive pulmonary disease

Risk ratios are age, gender and race stratified, and adjusted for state of residence

${ }^{\mathrm{a}}$ Warm-season average of daily 1-h maximum ozone concentrations

${ }^{\mathrm{b}}$ Models adjusted for 1-year moving average $\mathrm{PM}_{2.5}$ exposures

respiratory-related causes $(1.036 ; 95 \%$ CI: 1.032, 1.039)., with $\mathrm{O}_{3}$ exposure linked to 1.065 times the risks of COPD (95\% CI: $1.060,1.069)$ and 1.024 times that of pneumonia (95\% CI: $1.018,1.030)$ deaths per $10 \mathrm{ppb}$ increase in $\mathrm{O}_{3}$ exposures. Additionally, $\mathrm{O}_{3}$ exposures were associated with increased risk of CVD-related mortality $(1.027 ; 95 \% \mathrm{CI}$ : $1.025,1.028)$. For specific causes of CVD mortality, an increase in warm-season 1-h maximum $\mathrm{O}_{3}$ exposure was significantly associated with 1.052 times the risk of CHF mortality (95\% CI: 1.045, 1.060), 1.043 times the risks of IHD (95\% CI: $1.041,1.045)$ and 1.012 times that of CBV mortality (95\% CI: $1.008,1.016)$. One-hour maximum $\mathrm{O}_{3}$ exposure was also associated with increased risk of lung cancer mortality $(1.016 ; 95 \%$ CI: $1.011,1.020)$, but not mortality from all cancers $(1.000 ; 95 \%$ CI: $0.998,1.003)$.

In models adjusting for $\mathrm{PM}_{2.5}, \mathrm{O}_{3}$-associated mortality risks remained significant and positive for all causes of death, except for CBV and pneumonia (Table 2). For several causes of death, $\mathrm{PM}_{2.5}$-adjusted associations were attenuated, with RRs decreasing slightly to 1.030 (95\% CI: $1.027,1.034)$ for respiratory mortality and more substantially to 1.005 (95\% CI: $1.003,1.007)$ for CVD mortality per $10 \mathrm{ppb}$ increase in long-term $\mathrm{O}_{3}$. In contrast, for COPD and CHF mortality, RRs increased after adjustment for $\mathrm{PM}_{2.5}$, resulting in a $1.072(95 \% \mathrm{CI}: 1.067,1.077)$ and 1.063 (95\% CI: $1.055,1.071)$ times increase in risk per 10 ppb increase in $\mathrm{O}_{3}$, respectively. 
Table 3 Mortality RRs $(95 \% \mathrm{CI})$ associated with a $10 \mathrm{ppb}$ increase in temporal and spatio-temporal $\mathrm{O}_{3}$ : non-adjusted vs. $\mathrm{PM}_{2.5}$-adjusted model

\begin{tabular}{|c|c|c|c|c|}
\hline \multirow[t]{2}{*}{ Cause of death } & \multicolumn{2}{|l|}{ Base model $^{\mathrm{a}}$} & \multicolumn{2}{|l|}{$\mathrm{PM}_{2.5}$-adjusted model ${ }^{\mathrm{b}}$} \\
\hline & Temporal & Spatio-temporal & Temporal & Spatio-temporal \\
\hline All-cause & $1.184(1.177-1.190)$ & $0.990(0.988-0.993)$ & $1.176(1.170-1.182)$ & $0.990(0.988-0.993)$ \\
\hline Accidental & $0.979(0.945-1.014)$ & $1.004(0.987-1.022)$ & $0.982(0.947-1.017)$ & $1.004(0.987-1.021)$ \\
\hline All cardiovascular & $1.430(1.419-1.442)$ & $0.980(0.976-0.984)$ & $1.408(1.397-1.420)$ & $0.980(0.977-0.984)$ \\
\hline IHD & $1.570(1.552-1.588)$ & $0.978(0.972-0.983)$ & $1.536(1.519-1.554)$ & $0.979(0.973-0.984)$ \\
\hline $\mathrm{CBV}$ & $1.518(1.488-1.548)$ & $0.977(0.968-0.987)$ & $1.489(1.460-1.520)$ & $0.978(0.969-0.987)$ \\
\hline $\mathrm{CHF}$ & $1.137(1.101-1.173)$ & $0.991(0.976-1.007)$ & $1.138(1.102-1.175)$ & $0.991(0.976-1.007)$ \\
\hline All respiratory & 1.178 (1.159-1.197) & $0.985(0.977-0.992)$ & $1.170(1.151-1.189)$ & $0.985(0.977-0.992)$ \\
\hline COPD & $1.059(1.035-1.082)$ & $0.991(0.980-1.001)$ & $1.057(1.033-1.080)$ & $0.990(0.980-1.001)$ \\
\hline Pneumonia & $1.569(1.521-1.617)$ & $0.972(0.958-0.986)$ & $1.540(1.493-1.589)$ & $0.972(0.959-0.986)$ \\
\hline All cancer & $1.131(1.118-1.144)$ & $0.990(0.985-0.995)$ & $1.126(1.113-1.139)$ & $0.990(0.985-0.996)$ \\
\hline Lung cancer & $1.117(1.093-1.141)$ & $0.992(0.982-1.003)$ & $1.114(1.090-1.138)$ & $0.992(0.982-1.003)$ \\
\hline
\end{tabular}

Time period: 2000-2008, USA

$R R$ risk ratio, $C I$ confidence interval, $P M_{2.5}$ particles with aerodynamic diameters $<2.5 \mu \mathrm{m}, I H D$ ischemic heart disease, $C B V$ cerebrovascular disease, $C H F$ congestive heart failure, $C O P D$ chronic obstructive pulmonary disease

Risk ratios are age, gender and race stratified, and adjusted for state of residence

${ }^{a}$ Warm-season average of daily 1-h maximum ozone concentrations

${ }^{\mathrm{b}}$ Models adjusted for 1-year moving average $\mathrm{PM}_{2.5}$ exposures

In models adjusting for $\mathrm{NO}_{2}, \mathrm{O}_{3}$-associated mortality risks remained unchanged for respiratory and lung cancer, increased slightly for CHF and COPD, and were slightly attenuated for other causes of death (Table S2, SI). Associations were generally robust to adjustment for temperature (Table S3, SI). As shown on Table S4 (SI), RRs of the $\mathrm{PM}_{2.5}$-adjusted association between warm-season 1-h maximum $\mathrm{O}_{3}$ and mortality were essentially unchanged after adjustment for potential confounding by ecologic covariates from the 2000 U.S. Census or county-level behavioral covariates from BRFSS.

When we examined the potential for unmeasured confounding, we found statistically significant, positive RRs for temporal $\mathrm{O}_{3}$ and negative RRs for spatio-temporal $\mathrm{O}_{3}$ in base models (Table 3). In two-pollutant models adjusting for $\mathrm{PM}_{2.5}$ (Table 3) and in multi-variable models adjusted for both $\mathrm{PM}_{2.5}$ and behavioral covariates (Table S5, SI), the magnitude of "temporal" RRs decreased for all causes, especially in the multi-variate model, but the "spatio-temporal" RRs remained unchanged.

Risks of death were higher for beneficiaries living in non-urban as compared to urban areas for all-cause and CVD mortality, but were similar for respiratory and COPD mortality (Table S6, SI). For all causes of death, $\mathrm{O}_{3}$-associated mortality risks were highest in the Northeast and West as compared to the South and Midwest (Table S7, SI). Region-specific RRs were generally lower in $\mathrm{PM}_{2.5}$-adjusted as compared to non-adjusted models for all regions except the Northeast, for which RRs were generally comparable.
We examined the robustness of our results to the $\mathrm{O}_{3}$ exposure measure (Table 4). In $\mathrm{PM}_{2.5}$-adjusted models, RRs based on the warm-season average of 8 -h maximum $\mathrm{O}_{3}$ were similar for mortality from all causes, CHF, all respiratory, COPD, and lung cancer, but were attenuated and no longer significant for CVD and IHD mortality [note that associations between warm-season 8-h maximum $\mathrm{O}_{3}$ and both CVD and IHD mortality were significant and positive in single pollutant models, suggesting confounding of 8-h maximum-but not 1-h maximum associations-by $\mathrm{PM}_{2.5}$ (Table S8, SI)]. Findings for warm-season averages of 24-h $\mathrm{O}_{3}$ mirrored those for 8-h maximum $\mathrm{O}_{3}$, although associations with all-cause mortality were no longer positive.

\section{Discussion}

In our cohort of over 22 million Medicare beneficiaries, we found consistent associations between long-term $\mathrm{O}_{3}$ exposures and increased mortality. Specifically, we found a $0.4 \%, 3.0 \%, 0.5 \%$, and $1.5 \%$ increased risk in all-cause, respiratory, cardiovascular and for the first-time, lung cancer mortality, respectively, per $10 \mathrm{ppb}$ increase in warmseason average, 1-h maximum $\mathrm{O}_{3}$ exposure in $\mathrm{PM}_{2.5^{-}}$ adjusted models.

Notably, we found increased mortality risks from longterm $\mathrm{O}_{3}$ exposures to be the strongest and most consistent for respiratory-related diseases (including all respiratory and COPD), CHF, and lung cancer mortality, with no evidence 
Table 4 Mortality RRs $(95 \%$ CI) associated with a $10 \mathrm{ppb}$ increase in different $\mathrm{O}_{3}$ exposure measures

\begin{tabular}{llll}
\hline Cause of death & $1-\mathrm{h} \mathrm{Max}_{3}^{\mathrm{a}}$ & $8-\mathrm{h} \mathrm{Max}_{3} \mathrm{O}_{3}$ & 24-h Average $\mathrm{O}_{3}$ \\
\hline All-cause & $1.004(1.003-1.006)$ & $1.002(1.001-1.003)$ & $0.990(0.988-0.991)$ \\
$\quad$ Accidental & $1.010(1.002-1.017)$ & $1.018(1.009-1.027)$ & $1.025(1.014-1.036)$ \\
All cardiovascular & $1.005(1.003-1.007)$ & $0.997(0.995-0.999)$ & $0.973(0.970-0.975)$ \\
$\quad$ Ischemic heart disease & $1.008(1.006-1.011)$ & $0.996(0.993-0.999)$ & $0.964(0.960-0.967)$ \\
$\quad$ Cerebrovascular disease & $0.993(0.989-0.997)$ & $0.987(0.982-0.991)$ & $0.968(0.962-0.974)$ \\
$\quad$ Congestive heart failure & $1.063(1.055-1.071)$ & $1.072(1.063-1.080)$ & $1.066(1.056-1.077)$ \\
All respiratory & $1.030(1.027-1.034)$ & $1.033(1.030-1.037)$ & $1.021(1.016-1.026)$ \\
$\quad$ COPD & $1.072(1.067-1.077)$ & $1.084(1.079-1.089)$ & $1.084(1.077-1.091)$ \\
$\quad$ Pneumonia & $0.990(0.984-0.996)$ & $0.978(0.972-0.985)$ & $0.935(0.927-0.944)$ \\
All cancer & $0.995(0.993-0.998)$ & $0.993(0.990-0.995)$ & $0.983(0.980-0.986)$ \\
$\quad$ Lung cancer & $1.015(1.010-1.020)$ & $1.016(1.011-1.021)$ & $1.007(1.000-1.014)$ \\
\hline
\end{tabular}

Time period: $2000-2008$, USA

$R R$ risk ratio, $C I$ confidence interval, $I H D$ ischemic heart disease, $C B V$ cerebrovascular disease, $C H F$ congestive heart failure, $C O P D$ chronic obstructive pulmonary disease

Risk ratios are age, gender and race stratified, and adjusted for state of residence and 1-year moving average $\mathrm{PM}_{2.5}$ exposures

${ }^{\mathrm{a}}$ Warm-season average of daily ozone concentrations of confounding by $\mathrm{PM}_{2.5}, \mathrm{NO}_{2}$, or temperature or of sensitivity to the exposure measure. $\mathrm{O}_{3}$-associated $\mathrm{RRs}$ for respiratory-related mortality, for example, were not attenuated in models controlling for $\mathrm{PM}_{2.5}$ or $\mathrm{NO}_{2}$ and further were comparable for beneficiaries living in urban and nonurban areas, for which the composition of $\mathrm{PM}_{2.5}$ differs substantially [12, 13]. In contrast, associations between long-term $\mathrm{O}_{3}$ exposures and CVD-related mortality were less consistent, confounded by $\mathrm{PM}_{2.5}$ as evidenced by their attenuation in two-pollutant models and their stronger effects in non-urban as compared to urban environments. Further, we found $\mathrm{O}_{3}$-associated risks to vary with the exposure measure, with associations no longer significantly positive when warm-season 8-h maximum or 24-h average $\mathrm{O}_{3}$ was used to assess exposures, suggesting that long-term peak rather than average exposures reduce life expectancy. Altogether, these findings provide strong evidence that long-term peak $\mathrm{O}_{3}$ exposure is associated with mortality from respiratory-related causes and for the first-time lung cancer, but raise questions regarding $\mathrm{O}_{3}$-related impacts on CVD mortality.

Our findings were robust to further adjustment by ecological and behavioral covariates for all causes of death. They, however, likely remain affected by some unmeasured confounding, as suggested by the unequal coefficients for temporal and spatio-temporal $\mathrm{O}_{3}$. Our finding of unmeasured confounding, even after adjustment for $\mathrm{PM}_{2.5}$ and behavioral covariates, is not surprising given our reliance on administrative mortality data, which precludes us from controlling for covariates describing individual-specific SES, behaviors, and health histories, as was done in the CanCHEC study [3]. Despite this, findings from our study are consistent with previous studies of ozone and mortality, many of which did adjust for numerous individual-specific covariates. Of these studies, only Jerrett et al. [1] assessed $\mathrm{O}_{3}$ exposures for 448,850 ACS CPS-II (Cancer Prevention Study II) study participants as warm-season averages of daily 1 -h maximum ozone concentrations, finding significant, positive associations for cardiovascular (1.011, 95\% CI: 1.003, 1.023), IHD (1.015, 95\% CI: 1.003, 1.026), respiratory $(1.029,95 \% \mathrm{CI}: 1.010,1.048)$ and cardiopulmonary $(1.014,95 \% \mathrm{CI}: 1.007,1.022)$ mortality as in our study, but not for all-cause mortality $(1.001,95 \% \mathrm{CI}$ : $1.996,1.007)$, in contrast to our study. Further, associations in the CPS-II cohort remained significant after adjustment for $\mathrm{PM}_{2.5}$ for mortality from respiratory but not from cardiovascular-related causes, which like our study suggests confounding by $\mathrm{PM}_{2.5}$ of $\mathrm{O}_{3}$-mortality associations for cardiovascular-related causes [1].

In a follow-up to the CPS-II study [2], the impact of long-term $\mathrm{O}_{3}$ exposures on cause-specific mortality was reexamined using new estimates of ambient $\mathrm{O}_{3}, \mathrm{PM}_{2.5}$, and $\mathrm{NO}_{2}$ concentrations, a larger number of participants, and an extended follow-up period. The new $\mathrm{O}_{3}$ exposure estimates were based on individual-specific measures of yearly and summer-only 8-h maximum $\mathrm{O}_{3}$ averaged between 2002-2004 concentrations, thus capturing spatial but not temporal variability in $\mathrm{O}_{3}$ exposures. As in the original CPS-II and in our study, the follow-up study found summer 8-h daily maximum $\mathrm{O}_{3}$ exposures to be significantly and positively associated with all-cause $(1.02,95 \% \mathrm{CI}: 1.02$, $1.03)$, respiratory $(1.10,95 \% \mathrm{CI}: 1.07,1.12)$, and COPD (1.08, 95\% CI: $1.05,1.12)$ mortality and consistent with the original CPS-II but not our study, reported null associations 
with lung cancer mortality. Null associations with lung cancer in the CPS-II studies may be attributed to the relatively small number of lung cancer deaths in CPS-II, even after extended follow-up, with a total of 16,432 as compared to over 350,000 lung cancer deaths in our study. Notably the extended CPS-II study also reported new, significant increased risks of CVD $(1.02,95 \%$ CI: $1.01,1.04)$ and CBV (1.03, 95\% CI: 1.01, 1.06) mortality, associated with summer average 8-h maximum $\mathrm{O}_{3}$, even after adjustment for $\mathrm{PM}_{2.5}$. It is possible, however, that their observed increased risks for CVD and CBV reflect incomplete control for confounding by $\mathrm{PM}_{2.5}$, given (1) their time invariant exposure assessment method, with both $\mathrm{O}_{3}$ and $\mathrm{PM}_{2.5}$ exposures estimated as the average value over multiple years, with the number of years differing substantially for the two pollutants, and (2) evidence of confounding of associations between $\mathrm{O}_{3}$ and CVD mortality by $\mathrm{PM}_{2.5}$ in our study and in the original CPS-II.

For mortality from all causes, CVD, IHD, CBV, pneumonia, and all cancers, our non-positive findings for warmseason averages of 24-h $\mathrm{O}_{3}$ in $\mathrm{PM}_{2.5}$-adjusted models are consistent with those from Lipsett et al. [4] in the California Teachers study, which reported null associations between summer averaged 24-h $\mathrm{O}_{3}$ and all-cause, cardiovascular, non-malignant respiratory, and CBV mortality, and significant associations with increased mortality for IHD in single, but not 2-pollutant models that included $\mathrm{PM}_{2.5}$. While Lipsett et al. found null associations between 24-h $\mathrm{O}_{3}$ and lung cancer, we found these associations to be significant and positive. The insignificant associations for lung cancer and other causes of death reported by Lipsett et al. [4] have been attributed to its relatively small sample size of approximately 125,000 women. Our results suggest that its use of warm-season averages of 24-h $\mathrm{O}_{3}$ as the exposure measure may also contribute to the observed null findings.

More puzzling are results from Crouse et al. [3], who used data from the CanCHEC to examine the association between warm-season averages of 8-h maximum $\mathrm{O}_{3}$ and a number of causes of death. The authors reported significant increased $\mathrm{O}_{3}$-associated risks of all-cause mortality (1.031, 95\% CI: 1.026, 1.036), and null association for CBV $(0.981,95 \%$ CI: $0.961,1.001)$ as in our study, but null associations with lung cancer (1.006, 95\% CI: 0.990, 1.023) mortality and significant positive associations with mortality from CVD (1.037, 95\% CI: 1.028, 1.047), and diabetes (1.156, 95\% CI: 1.121, 1.190), even after adjustment for $\mathrm{PM}_{2.5}$ and $\mathrm{NO}_{2}$. The $\mathrm{O}_{3}$-associated risks of increased CVD mortality-together with observed null associations between $\mathrm{PM}_{2.5}$ and CVD mortality-caused the authors to hypothesize that the multi-pollutant results were affected by collinearity among the multiple pollutants and/or overlapping spatial patterns in $\mathrm{O}_{3}$ and $\mathrm{PM}_{2.5}$.
Support for this hypothesis is provided by our findings of effect modification of the $\mathrm{O}_{3}$-mortality relationship by region for each cause of death. One possible explanation for this region-specific variability in $\mathrm{O}_{3}$-mortality risks may be corresponding regional variability in the correlation between $\mathrm{O}_{3}$ and $\mathrm{PM}_{2.5}$, which may result in differential confounding by $\mathrm{PM}_{2.5}$ of regional $\mathrm{O}_{3}$ effects on mortality. Other factors that may contribute to observed heterogeneity in $\mathrm{O}_{3}$-mortality associations may also include regional differences in (1) $\mathrm{PM}_{2.5}$ composition, which may differentially confound $\mathrm{O}_{3}$-mortality associations, (2) air conditioning prevalence, which may contribute to differential exposure error, and (3) unmeasured confounders that were not captured by our control for strata for age, race, gender, and our adjustment for state of residence, $\mathrm{PM}_{2.5}$, census, and behavioral variables. Note that certain causes of death, such as pneumonia or CBV, may be more sensitive to the regionspecific effects of confounding, due to their small number of deaths.

Importantly, our positive and consistent associations linking long-term peak $\mathrm{O}_{3}$ exposures to cardio-respiratory mortality are biologically plausible. Numerous studies have demonstrated the negative permanent effects of long-term exposure to $\mathrm{O}_{3}$ on pulmonary function and increased lung inflammation [14-22], which may lead to tissue injury [14], airway remodeling $[15,16]$, and pulmonary fibrotic changes [17]. Further, exposed animals were shown to exhibit similar or greater morphological and other changes after episodic as compared to continuous $\mathrm{O}_{3}$ exposures [18], lending support for our findings showing that warm-season averages of 1-h daily maximum $\mathrm{O}_{3}$ were more relevant to mortality as compared to 8 -h daily maximum and 24-h average $\mathrm{O}_{3}$ exposures.

Our study has several limitations. First, we did not have information on beneficiaries' activity and mobility patterns, which may contribute to exposure misclassification. Further, we used ambient, nearest monitor $\mathrm{O}_{3}$ concentrations to assess exposures, which are imperfect proxies of personal $\mathrm{O}_{3}$ exposures. This exposure error has been shown to bias RR estimates towards the null [23], possibly suggesting that the magnitudes of our associations are underestimated. We, however, minimized other sources of exposure error by (1) linking $\mathrm{O}_{3}$ exposure to beneficiary information by year in order to account for residential moves and ZIP code boundary changes and (2) using exposure values that were geographically close to residences, capturing exposures that result from nearby $\mathrm{O}_{3}$ emission sources, and thus reducing the potential for exposure misclassification. Second, although we did not have data on personal-level characteristics, we adjusted for county-level behavioral variables, including those related to smoking and comorbidities, with results essentially unchanged, consistent with little, if any, confounding of $\mathrm{O}_{3}$-mortality associations by the 
examined covariates. While our findings showed that adjusting for $\mathrm{PM}_{2.5}$ and behavioral covariates reduces unmeasured confounding, note that differences in the coefficients for temporal and spatio-temporal $\mathrm{O}_{3}$ remained, suggesting unmeasured confounding of the $\mathrm{O}_{3}$-mortality associations. These findings demonstrate the need for additional studies to examine the impact of unmeasured confounding on estimated risks posed by long-term $\mathrm{O}_{3}$ on mortality. Lastly, our findings may not be generalizable to younger age groups or to beneficiaries living away from monitors.

These limitations are balanced by the substantial strengths of our study and long time period of study. With more than 22 million Medicare beneficiaries with near 5.8 million deaths over the 9 years of study period, our study is well powered to detect meaningful associations for mortality from specific causes, allowing us to provide valuable, new information on the relationship between $\mathrm{O}_{3}$ exposures and specific CVD, respiratory and cancer-related deaths in addition to all-cause mortality.

\section{Code availability}

All analyses were performed using SAS 9.4 Software (SAS Institute Inc., Cary, North Carolina). SAS code used to generate the results is provided as supplementary information (Supplementary Appendix 2, SI).

Acknowledgements This work was supported by Electric Power Research Institute grant 00-10003095. The data that support the findings of this study are available from the US Environmental Protection Agency (EPA) Air Quality System, the Centers for Medicare and Medicaid Services, US Census Bureau and Behavioral Risk Factor Surveillance System. We acknowledge Dr. Jeffrey Yanosky of Pennsylvania State University (State College, Pennsylvania) for providing daily $\mathrm{PM}_{2.5}$ grid data.

\section{Compliance with ethical standards}

Conflict of interest The authors declare that they have no conflict of interest.

Publisher's note: Springer Nature remains neutral with regard to jurisdictional claims in published maps and institutional affiliations.

Open Access This article is licensed under a Creative Commons Attribution 4.0 International License, which permits use, sharing, adaptation, distribution and reproduction in any medium or format, as long as you give appropriate credit to the original author(s) and the source, provide a link to the Creative Commons license, and indicate if changes were made. The images or other third party material in this article are included in the article's Creative Commons license, unless indicated otherwise in a credit line to the material. If material is not included in the article's Creative Commons license and your intended use is not permitted by statutory regulation or exceeds the permitted use, you will need to obtain permission directly from the copyright holder. To view a copy of this license, visit http://creativecommons. org/licenses/by/4.0/.

\section{References}

1. Jerrett M, Burnett RT, Pope CA, III, Ito K, Thurston G, Krewski $\mathrm{D}$, et al. Long-term ozone exposure and mortality. N Engl J Med. 2009;360:1085-95.

2. Turner MC, Jerrett M, Pope CA, III, Krewski D, Gapstur SM, Diver $\mathrm{WR}$, et al. Long-term ozone exposure and mortality in a large prospective study. Am J Respir Crit Care Med. 2016;193:1134-42.

3. Crouse DL, Peters PA, Hystad P, Brook JR, van Donkelaar A, Martin RV, et al. Ambient $\mathrm{PM}_{2.5}, \mathrm{O}_{3}$, and $\mathrm{NO}_{2}$ exposures and associations with mortality over 16 years of follow-up in the Canadian Census Health and Environment Cohort (CanCHEC). Environ Health Perspect. 2015;123:1180-6.

4. Lipsett MJ, Ostro BD, Reynolds P, Goldberg D, Hertz A, Jerrett $\mathrm{M}$, et al. Long-term exposure to air pollution and cardiorespiratory disease in the California teachers study cohort. Am J Respir Crit Care Med. 2011;184:828-35.

5. Greven S, Dominici F, Zeger S. An approach to the estimation of chronic air pollution effects using spatio-temporal information. $\mathrm{J}$ Am Stat Assoc. 2011;106:396-406.

6. Pun VC, Kazemiparkouhi F, Manjourides J, Suh HH. Long-term PM2.5 exposure and respiratory, cancer, and cardiovascular mortality in older US adults. Am J Epidemiol. 2017;186:961-9.

7. Eum K, Kazemiparkouhi F, Wang B, Manjourides J, Pun VC, Pavlu V, et al. Long-term $\mathrm{NO}_{2}$ exposures and cause-specific mortality in american older adults. Environ Int. 2019;124:10-5.

8. Yanosky JD, Paciorek CJ, Laden F, Hart JE, Puett RC, Liao D, et al. Spatio-temporal modeling of particulate air pollution in the conterminous United States using geographic and meteorological predictors. Environ Health. 2014;13:63.

9. Bechle MJ, Millet DB, Marshall JD. National spatiotemporal exposure surface for $\mathrm{NO}_{2}$ : Monthly scaling of a satellite-derived land-use regression, 2000-2010. Environ Sci Technol. 2015;49:12297-305.

10. United States Census Bureau. 2000 Census. U.S. Census Bureau. 2000. https://www.census.gov/main/www/cen2000.html. Accessed 26 Feb 2016.

11. Behavioral Risk Factor Surveillance System (BRFSS). SMART (the Selected Metropolitan/Micropolitan Area Risk Trends): BRFSS City and County Data and Documentation. 2014. https://www.census.gov/main/www/cen2000.html. Accessed 16 Oct 2015.

12. Zheng M, Cass GR, Schauer JJ, Edgerton ES. Source apportionment of $\mathrm{PM}_{2.5}$ in the southeastern United States using solventextractable organic compounds as tracers. Environ Sci Technol. 2002;36:2361-71.

13. Turpin BJ, Lim H. Species contributions to $\mathrm{PM}_{2.5}$ mass concentrations: Revisiting common assumptions for estimating organic mass. Aerosol Science \& Technology. 2001;35:602-10.

14. Balmes JR, Chen LL, Scannell C, Tager I, Christian D, Hearne $\mathrm{PQ}$, et al. Ozone-induced decrements in FEV1 and FVC do not correlate with measures of inflammation. Am J Respir Crit Care Med. 1996;153:904-9.

15. Harkema JR, Hotchkiss JA, Barr EB, Bennett CB, Gallup M, Lee JK, et al. Long-lasting effects of chronic ozone exposure on rat nasal epithelium. Am J Respir Cell Mol Biol. 1999;20:517-29.

16. Hotchkiss JA, Harkema JR, Henderson RF. Effect of cumulative ozone exposure on ozone-induced nasal epithelial hyperplasia and secretory metaplasia in rats. Exp Lung Res. 1991;15:589-600.

17. Mudway IS, Kelly FJ. Ozone and the lung: a sensitive issue. Mol Aspects Med. 2000;21:1-48.

18. Tyler WS, Tyler NK, Last JA, Gillespie MJ, Barstow TJ. Comparison of daily and seasonal exposures of young monkeys to ozone. Toxicology. 1988;50:131-44.

19. Paige RC, Wong V, Plopper CG. Long-term exposure to ozone increases acute pulmonary centriacinar injury by 1 - 
nitronaphthalene: II. Quantitative histopathology. J Pharmacol Exp Ther. 2000b;295:942-50.

20. Kleeberger SR, Ohtsuka Y, Zhang LY, Longphre M. Airway responses to chronic ozone exposure are partially mediated through mast cells. J Appl Physiol. 2001b;90:713-23.

21. Catalano PJ, Chang L, Harkema JR, Kaden DA, Last JA, Mellick $\mathrm{PW}$, et al. Consequences of prolonged inhalation of ozone on F344/N rats: Collaborative studies Part XI: Integrative summary. Res Rep Health Eff Inst. 1995;(65 Pt 11):1-85.
22. Pinkerton KE, Weller BL, Ménache MG, Plopper CG. Consequences of prolonged inhalation of ozone on F344/N rats: collaborative studies. Part XIII. A comparison of changes in the tracheobronchial epithelium and pulmonary acinus in male rats at 3 and 20 months. Res Rep Health Eff Inst. 1998;65:1-37.

23. Delfino RJ, Coate BD, Zeiger RS, Seltzer JM, Street DH, Koutrakis P. Daily asthma severity in relation to personal ozone exposures and outdoor fungal spores. Am J Respir Crit Care Med. 1996;154:633-41. 